\title{
Statistics on indigenous peoples: International effort needed
}

\author{
Richard Madden $^{\mathrm{a}, *}$, Per Axelsson ${ }^{\mathrm{b}}$, Tahu Kukutai ${ }^{\mathrm{c}}$, Kalinda Griffiths $^{\mathrm{a}}$, Christina Storm Mienna $^{\mathrm{b}}$, \\ Ngaire Brown ${ }^{\mathrm{d}}$, Clare Coleman ${ }^{\mathrm{a}}$ and Ian Ring ${ }^{\mathrm{e}}$ \\ ${ }^{a}$ Sydney Centre for Aboriginal and Torres Strait Islander Statistics, University of Sydney, Sydney, Australia \\ ${ }^{\mathrm{b}}$ Umea University, Umea, Australia \\ ${ }^{\mathrm{c}}$ National Institute of Demographic and Economic Analysis, The University of Waikato, Waikato, Australia \\ ${ }^{\mathrm{d}}$ National Aboriginal Controlled Community Health Organisation, Australia \\ e University of Wollongong, Wollongong, Australia
}

\begin{abstract}
In 2007, the UN General Assembly endorsed the United Nations Declaration on the Rights of Indigenous Peoples. In the following years, there has been a strong call from a range United Nations agencies and spokespersons for countries to act to improve their statistics relating to Indigenous peoples as part of their response to the Declaration. These calls have emphasised the need for a holistic approach, describing strengths and resilience of Indigenous peoples and not just a focus on gaps and disadvantage. National responses have been mixed and overall statistics remain inadequate. Significantly, there has been no international statistical effort through the United Nations statistical structures to respond to the Declaration and the increasing array of calls for improved statistics. The United Nations Statistical Commission in particular has an array of mechanisms to study statistical needs and develop solutions across a broad international statistical agenda. It is time for countries to make a concerted effort to improve their own statistics on Indigenous peoples, and to insist that the Statistical Commission work in partnership with the Permanent Forum on Indigenous Issues and other stakeholders to lead a major international drive to improve statistics on and for Indigenous peoples.
\end{abstract}

Keywords: Indigenous statistics, international effort, indigenous rights

\section{Introduction}

The health and wellbeing of Indigenous peoples around the world has been repeatedly described in international and national reports for many years. The 2009 United Nations Report 'State of the World's Indigenous Peoples' [1] reported available national data on the extreme disadvantage of a range of Indigenous people, as well as describing the resilience of Indigenous peoples and their long struggle for recognition, including in international forums. The Report acknowledged that the data were indicative rather than systematic.

\footnotetext{
*Corresponding author: Richard Madden, Sydney Centre for Aboriginal and Torres Strait Islander Statistics, University of Sydney, Sydney, Australia. E-mail: richard.madden@sydney.edu.au.
}

A second edition of the Report was published in 2015 [2]. Statistics available continue to be indicative and show progress has been disappointing and often minimal, with many countries having no statistics on their Indigenous people at all.

The description of Indigenous peoples at national level was poor (and virtually non-existent) in many countries until the later part of the twentieth century, including in countries with otherwise well-developed statistical systems. The national reporting situation has improved, although exceptions are noted later. But there has continued to be no international effort in relation to Indigenous statistics. There is now a strong case for urgent attention to this lack of action, to make Indigenous peoples visible in their own countries and across the world, and to provide a strong base for policy development and monitoring. 


\section{Background}

The 2007 United Nations Declaration on the Rights of Indigenous Peoples [3] provides a comprehensive base for the full participation of Indigenous peoples in the broader society in which they may live or by which they may be governed, as well as a mandate for selfdetermination 'by virtue of which they freely determine their political status and freely pursue their economic, social and cultural development'.

The Declaration places the responsibility on Member States to "provide effective mechanisms for prevention of, and redress for ... Any action which has the aim or effect of depriving them of their integrity as distinct peoples or ethnic identities, or of their cultural values (Article 8)'. Further, Article 15 states 'Indigenous peoples have the right to the dignity and diversity of their cultures, traditions, histories and aspirations which shall be appropriately reflected in education and public information' (emphasis added).

The WHO's Commission on the Social Determinants of Health [4] in 2008 recommended that countries should have a 'Minimum Health Equity Surveillance System'. As part of the System, 'good-quality data on the health of Indigenous Peoples should be available, where applicable'.

In 2014, the UN General Assembly adopted the 'Outcome document of the high-level plenary meeting of the General Assembly known as the World Conference on Indigenous Peoples' [5]. Article 10 of that document states

'We commit ourselves to working with indigenous peoples to disaggregate data, as appropriate, or conduct surveys and to utilizing holistic indicators of indigenous peoples' well-being to address the situation and needs of indigenous peoples and individuals, in particular older persons, women, youth, children and persons with disabilities.'

There is then a clear direction to each Member State and its national statistical office/system, as part of the implementation of the Convention, to work in partnership with its Indigenous peoples to develop and implement an effective set of statistical information.

This direction is entirely in keeping with the United Nations Fundamental Principles of Official Statistics [6], adopted by the General Assembly in 2014, on the advice of the UN Statistical Commission which had itself endorsed the Principles in 1994. Principle 1 sets out the central role of official statistics in a Member State:
'Official statistics provide an indispensable element in the information system of a democratic society, serving the Government, the economy and the public with data about the economic, demographic, social and environmental situation. To this end, official statistics that meet the test of practical utility are to be compiled and made available on an impartial basis by official statistical agencies to honour citizens' entitlement to public information.'

These international agreements set the framework within which Member States should develop, collect and disseminate official statistics. Importantly, they also set clear directions for the United Nations and international statistical efforts and governance.

\section{Current performance: National}

Some National Statistical Offices/systems have made significant progress in describing the demography and economic and social status of Indigenous peoples, for example [78]. Population estimates, life expectancy and child mortality estimates are frequently available, although coverage may be limited and accuracy of estimates questionable. This effort is in many cases relatively recent: in Australia until 1967 there was a constitutional bar on including Aboriginal people in national population estimates.

Some countries with well-developed and highly respected national statistical systems have only partly developed statistics on their Indigenous populations, and in some cases, none at all.

Several Nordic countries (including Sweden and Norway) have legislative bans on identifying ethnicity in national statistical collections [9]. This prohibition was introduced as a means of avoiding discrimination. Despite a researcher based effort in Norway [10], the result is an absence of official national statistics on the numbers of and conditions for Sami people, and no representative basis for discussion of the policy and social implications.

Developments can sometimes be set back by specific policy decisions. Moves away from traditional censuses are under discussion in several countries with significant Indigenous populations. Information on small populations, especially if widely dispersed, is a special challenge for alternative means of enumerating and describing national populations. The implications for Indigenous peoples need careful thought and consideration with Indigenous peoples to ensure out- 
comes are effective for, and seen to be effective by, Indigenous peoples.

The situation in Canada has recently been thoroughly described by Smylie and Firestone [11]: discontinuation of the long form census in 2011 set back Indigenous statistical development, which already suffered from lack of Indigenous identifiers in several key data sets, including vital statistics in some provinces: the new Canadian Government has acted quickly to reintroduce the long form census [12].

While national efforts are to be applauded, they have significant shortcomings. There tends to be a strong focus on Indigenous disadvantage, including comparison with the non-Indigenous population, and a focus on governments' information needs. Diversity, culture, values and practices are largely ignored [13].

The development of the current focus on Indigenous disadvantage can be partly explained by the need for policy makers and governments to argue for resources to address entrenched Indigenous inequities. While there have been active consultation efforts by NSOs in countries such as Australia and New Zealand), the Indigenous arguments for a broader view of Indigenous peoples and for effective participation in data collection processes and governance through a partnership with Indigenous peoples have generally not been systematically addressed.

\section{Current performance: International}

At the international statistical level, there has been a lack of interest in Indigenous statistics. The UN Statistical Commission has never included Indigenous statistics on its agenda. The UN Statistics Division also appears from its website to have shown little interest in Indigenous issues, apart from use of Indigenous place names.

The Statistical Commission has well established mechanisms to take forward significant issues. These include ad hoc groups established by the Commission Chair ('Friends of the Chair') and groups to work over the medium term on major issues, known as City Groups (after the location of their first meeting). But these mechanisms have not been applied to Indigenous statistical issues.

Since 2005, an ad hoc International Group on Indigenous Health Measurement has generated cooperation between Indigenous peoples and national statistical agencies in Australia, New Zealand, Canada and the United States, with some useful output [16]. The
Group is currently finalising recommendations for best practice in Indigenous mortality estimation. Representatives from other countries have recently participated in the Group.

Meanwhile, the Economic and Social Council's Permanent Forum on Indigenous Issues addressed statistical issues in some detail at its April 2015 meeting [17]. It requested States to include the 'data disaggregation' recommendation from the outcome document of the World Conference on Indigenous Peoples into the Post 2015 Development Agenda. In doing so, the Forum noted the serious concerns raised by Indigenous peoples over the lack of explicit reference to and inclusion of Indigenous peoples as distinct groups in the Development Agenda.

After addressing the proposed Indigenous peoples' development index, the Forum called upon States to recognize Indigenous peoples, where they exist, consistent with the provisions of the United Nations Declaration, in their legislation in order to gather statistical data on them.

The United Nations Special Rapporteur on the rights of indigenous peoples has also drawn attention to the need for improved data on Indigenous peoples. Her 2015 report to the Human Rights Council [18] highlighted the 'systemic weaknesses in national data collection systems in relation to understanding indigenous peoples' and specified the lack of 'birth registration systems that robustly provide certification of the births of all indigenous children' in many countries.

In the Foreword to the United Nations 2015 State of the World's Indigenous Peoples [2], Wu Hongbo, Under-Secretary-General for Economic and Social Affairs, again described the disadvantages suffered by Indigenous peoples across the world (with emphasis on health and shortened life expectancy). He then refers to the lack of statistical effort: "At the same time, it is often difficult to obtain a global assessment of indigenous peoples' health status because of the lack of data. There has to be more work undertaken towards building on existing data collection systems to include data on indigenous peoples and their communities'. Likewise, the Indigenous Peoples Major Group on the UN's Sustainable Development Goals (SDGs) recently called on States to include an Indigenous identifier in official data collection to ensure adequate data disaggregation and effective monitoring of the SDGs [19]. 


\section{Proposed action agenda}

\subsection{National}

In light of the Fundamental Principles of Official Statistics, national statistical offices/systems have the responsibility to respond to the UN Declaration on the Rights of Indigenous Peoples, and in particular to the recommendation concerning statistics from the World Conference on Indigenous Peoples and reiterated by the Permanent Forum.

In particular, the Permanent Forum recommendation on gathering statistical data on Indigenous peoples should be pursued as a matter of urgency, notably by countries with well-resourced and otherwise comprehensive statistical systems (for example, the Nordic countries) which currently do not do so, provided that it is acceptable to the Indigenous peoples concerned. Where needed, there should be a concerted educational effort to make clear that the purpose of well-developed Indigenous statistics should be improving the wellbeing of Indigenous peoples, not increasing their disadvantage.

National statistical programs, including development of statistical concepts and methods, collection of statistics and their analysis and dissemination and Indigenous custodianship protocols, should be developed in partnership with the Indigenous peoples resident in each country. Consistent with the participation principles in the UN Declaration (Articles 18, 23), one way to ensure that Indigenous peoples have an active role in this process would be to mandate Indigenous representation on the various advisory bodies that assist NSOs. In Canada the First Nations Information Governance Centre and their principles of ownership, control, access and possession $\left(\mathrm{OCAP}^{\mathrm{TM}}\right)$ offer a practical example of what an autonomous community-driven model of partnership might look like [20]. Different approaches may be used in different Member States and for different Indigenous peoples but there needs to be a common long term financial and capacity building commitment.

The statistics should be based on sound concepts consistent with the UN Declaration, and must be collected and disseminated in an ethical manner.

Statistics should include the demographic characteristics and the economic and social status of Indigenous peoples, including the specific topics listed in Article 10 of the report of the 2014 World Conference on Indigenous Peoples (see above). The data collected should be relevant to the needs, cultural values and self-determining aspirations of Indigenous peoples, and be accessible to them for their own development purposes. This includes the collection of data that can be used for rights-based indicators, consistent with the Human Rights Based Development Approach promoted by the UN Permanent Forum on Indigenous Issues, the Special Rapporteur on the Rights of Indigenous Peoples and the Indigenous Peoples Major Group for the UN's SDGS.

\subsection{International}

The UN Statistical Commission, supported by the UN Statistics Division, should respond positively and quickly to the various recommendations from the World Conference on Indigenous Peoples and the Permanent Forum detailed above. The responsibility to do this stems directly from the UN Declaration on the Rights of Indigenous peoples and the Fundamental Principles of Official Statistics.

The Commission should develop and adopt a work program for Indigenous statistics. Specific measures should include a clear call for an Indigenous identifier based on self identification in population censuses and in birth and death registrations (or alternative measures).

As it has done for many other matters of significant importance, the Commission should give consideration to appointing a special purpose group (a Friends of the Chair Group in the first instance, and perhaps a City Group in the medium term) to work on Indigenous statistics. Any group established needs to include a significant number of Indigenous people as members, and to work in partnership with the Permanent Forum, the Special Rapporteur and other relevant groups.

Member States should report to the United Nations each three years on the state of statistics on Indigenous peoples, and a report should be compiled and published by the United Nations Statistical Division. The report should be provided to and discussed at the United Nations Permanent Forum on Indigenous Issues and at the United Nations Statistical Commission meetings immediately following its release.

\section{Conclusion}

A concerted and sustained effort is needed from the international statistical community to improve the statistics on and for Indigenous peoples. This effort would be most suitably led by the United Nations Sta- 
tistical Commission, to work with the Permanent Forum on Indigenous Issues to respond to the recommendations of the World Conference on Indigenous Peoples and subsequent resolutions of the Forum. Additionally, the Statistical Commission should put in place regular reporting and monitoring of international statistical effort on Indigenous statistics.

National statistical agencies should build on previous efforts to count and describe Indigenous peoples. They should actively build partnerships with Indigenous peoples to recognise Indigenous peoples in their statistical programs and to develop, collect and disseminate national plans for the achievement of a comprehensive range of statistics on and for Indigenous peoples.

\section{References}

[1] United Nations, Department of Economic and Social Affairs. State of the World's Indigenous Peoples: United Nations Publications, 2009.

[2] United Nations, Department of Economic and Social Affairs. State of the World's Indigenous Peoples: United Nations Publications, 2015.

[3] United Nations General Assembly. United Nations Declaration on the Rights of Indigenous Peoples: Adopted by the General Assembly on 13 September 2007: UN; 2008.

[4] World Health Organization, Commission on Social Determinants of Health. Closing the gap in a generation: health equity through action on the social determinants of health: Commission on Social Determinants of Health final report. Geneva, Switzerland: World Health Organization, Commission on Social Determinants of Health, 2008.

[5] United Nations General Assembly. Outcome document of the high-level plenary meeting of the General Assembly known as the World Conference on Indigenous Peoples. UN, 2014.

[6] United Nations General Assembly. Fundamental Principles of Official Statistics. UN, 2014.

[7] Australian Institute of Health and Welfare. The health and welfare of Australia's Aboriginal and Torres Strait Islander Peoples 2015. Canberra (AUST): AIHW, 2015 Cat. no. IHW 147.

[8] United Nations DoEaSA. Approaches to measuring Indigenous requirements for Official Statistics, Meeting of the Ex- pert Group on International Statistical Classifications 19-22 May 2015. New York: United Nations Publications, Division S; 2015.

[9] P. Axelsson, ' In the national registry, all people are equal': Sami in Swedish statistical sources, 2011, pp. 117-33.

[10] T. Pettersen and M. Brustad, Which Sami? Sami inclusion criteria in population-based studies of Sami health and living conditions in Norway - an exploratory study exemplified with data from the SAMINOR study, International Journal of Circumpolar Health 72(1) (2013), 1-11.

[11] J. Smylie and M. Firestone, Back to the basics: Identifying and addressing underlying challenges in achieving high quality and relevant health statistics for indigenous populations in Canada, Statistical Journal of the IAOS 31(1) (2015), 67-87.

[12] Minister of Innovation, Science and Economic Development Mandate Letter, http://pm.gc.ca/eng/minister-innovation-scie nce-and-economic-development-mandate-letter, Oct 2015.

[13] T. Kukutai and M. Walter, Recognition and indigenizing official statistics: Reflections from Aotearoa New Zealand and Australia, Statistical Journal of the IAOS 31(2) (2015), 317326.

[14] Australian Institute of Health and Welfare. Measuring the social and emotional wellbeing of Aboriginal and Torres Strait Islander peoples. Canberra (AUST): AIHW, 2009 Cat. no. IHW 24.

[15] J. Taylor and T. Kukutai, Data Sovereignty for Indigenous Peoples: Current Practice and Future Needs (9-10 July 2015), Report to the Academy of the Social Sciences in Australia on the Workshop 2015 [cited 201513 Nov]. Available from: https://cms.assa.edu.au/.pdf/reports/Data\%20Sovereignty\% 20for\%20Indigenous\%20People.pdf.

[16] Australian Institute of Health and Welfare. Comparing life expectancy of indigenous people in Australia, New Zealand, canda and the United States: conceptual, methodological and data issues. Canberra: AIHW, 2011.

[17] Permanent Forum on Indigenous Issues. Report of the Fourteenth Session, 20 April-1 May 2015. 2015.

[18] V.T. Corpuz, Report of the Special Rapporteur on the rights of indigenous peoples. UN General Assembly Human Rights Council, 2015.

[19] Indigenous Peoples Major Group. Position Paper on Proposed SDG Indicators 2015 [cited 201513 Nov]. Available from: http://tebtebba.org/index.php/content/357-indigenouspeoples-major-group-position-paper-on-proposed-sdgindicators.

[20] First Nations Governance Information Centre. Barriers and Levers for the Implementation of OCAP, The International Indigenous Policy Journal 5(2) (2014), 1-11. 